\title{
O uso de simuladores via smartphone no ensino de ciência como ferramenta pedagógica na abordagem de conteúdos contextualizados de Física
}

The use of simulators via smartphone in the teaching of science as a pedagogical tool in addressing physics contextualized content

\author{
C. D. Barbosa*; N. N Soares; M. L. das Chagas; F. C. L. Ferreira \\ Programa de Pós-Graduação em Ensino de Física, Universidade Federal do Sul e Sudeste do Pará, 68500-000, \\ Marabá - PA, Brasil. \\ *cairodb@gmail.com
}

(Recebido em 05 de setembro de 2016; aceito em 24 de outubro de 2016)

\begin{abstract}
Neste trabalho, discutiram-se metodologias voltadas para o uso de simuladores via smartphone no ensino de conceitos e fenômenos físicos estudados na disciplina de Ciências Naturais nas séries finais do ensino fundamental, como exemplo, utilizamos temas de óptica. Muito docentes enfrentam o problema do uso impróprio de celulares smartphones pelos alunos durante as aulas, pois os mesmos acabam sendo motivo de distração. Pensando nisso a proposta desse trabalho é expor exemplos de como utilizar esta tecnologia inovadora de forma pedagógica no ensino de Ciências através de simuladores interativos. Para isso foi realizada uma pesquisa bibliográfica referente às teorias de aprendizagem e pesquisas voltadas para o uso destas tecnologias midiáticas no ensino. Objetivou-se assim, dar aos conteúdos de Física abordados no ensino fundamental um caráter menos abstrato, assim como, proporcionar ao discente um papel mais ativo e interativo no processo de ensino e aprendizagem.
\end{abstract}

Palavras-chave: Simuladores, smartphone, ensino de Ciências, conteúdos de Física.

In this paper we discuss methodologies directed to the use of simulators via smartphone in teaching concepts and physical phenomena studied in the discipline of Natural Sciences in the final series of elementary school, for example, we used optical topics. Many teachers confront the problem of misuse of mobile phones by students during classes, because they end up being a distraction. Thinking about it the purpose of this work is to expose examples of how to use this innovative technology pedagogically in teaching science through interactive simulators. For this, was carried out a literature survey related to learning theories and research for the use of these media technologies in teaching. In order to give content Physics covered in elementary school a less abstract character, as well as provide the student a more active and interactive role in the process of teaching and learning.

Keywords: Simulators, smartphone, science teaching, content physics.

\section{INTRODUÇÃO}

Com o advento das Tecnologias de Informação e Comunicação (TIC) surge uma nova era no ensino, marcada dentre outros fatores, pelo anseio dos docentes por ferramentas que lhes possibilitem a promoção de uma aprendizagem significativa, construindo assim, ambientes de ensino mais interativos e instigantes aos educandos.

Dentre as TIC contemporâneas, aparelhos como smartphones e softwares como os simuladores, merecem destaque quanto às possibilidades de uso voltadas para o ensino, sobretudo para disciplinas como Ciências, que carecem de aulas experimentais e conteúdos apresentados de forma menos abstrata, especialmente ao se trabalhar com fenômenos físicos. Os simuladores dessa forma contribuem para esta ludicidade, ao permitir que o smartphone possa ser utilizado também, como uma espécie de laboratório virtual portátil.

É perceptível que os alunos passam grande parte do dia manuseando seus celulares, seja assistindo vídeos, se comunicando em redes sociais, realizando pesquisas, ouvindo musica, etc. No entanto o uso do celular em sala de aula sem a conexão com as aulas têm se tornado motivo 
de "guerra" entre alunos e docentes. Pensando nisso, por que não orientar o seu uso de forma pedagógica, tornando o aparelho uma ferramenta lúdica para a aprendizagem de diferentes conteúdos. Temos conhecimento que as mídias influenciam de forma intensa o cotidiano dos alunos, por isso educadores precisam explorar com mais intensidade estes recursos.

A Física é uma das áreas das ciências em que o indivíduo precisa de diferentes metodologias para que ocorra uma aprendizagem significativa. Nesse sentido, se torna incontestável a necessidade de aulas onde o discente possa vivenciar de forma mais palpável o assunto em estudo. Através do uso do smartphone, diversos softwares podem oferecer essa interatividade ao discente, como vídeos, jogos e principalmente o simulador. A utilização desta TIC permite que o saber científico seja potencializado, pois além de ser um equipamento portátil que cabe na palma da mão, este têm a vantagem de estimular vários sentidos, o que facilita uma aprendizagem efetiva, e também permitem maior compartilhamento de materiais e informações.

Existem escolas que não possuem laboratórios experimentais para as disciplinas das Ciências Naturais, ou nem mesmo possuem laboratórios de informática em condições de se trabalhar com uma turma completa, pois neste ambiente através de simuladores virtuais, por exemplo, é possível trabalhar com a simulação de diversos fenômenos físicos, que se aproximam da realidade.

Dessa forma, pensando nestas dificuldades encontradas por muitos alunos e educadores no ensino de Física, nas series finais do ensino fundamental e avaliando as possibilidades do uso de simuladores via smartphone durante as aulas, este artigo vem expor exemplos, de como aplicar estes recursos educacionais, em assuntos da Física de maneira contextualizada com outras áreas das Ciências Naturais. Para esse fim foi escolhido o tema "Defeitos da Visão" que relaciona tecnologia, conceitos de Física voltados para a óptica e conteúdos de Biologia.

Para o cumprimento ao proposto, utilizou-se de pesquisa teórica, buscando uma abordagem sobre o processo de ensino e aprendizagem e a quebra de alguns paradigmas, para então passar ao estudo do uso de simuladores gratuitos acessados via smartphone e formas de utilização de tais ferramentas como alternativas de metodologias de ensino para assuntos de Física no ensino fundamental.

\section{FUNDAMENTAÇÃO TEÓRICA}

Observa-se que o volume de informações que surgem a cada instante e a rapidez com que são renovados, torna-se insustentável o modelo de educação baseado no decorar. Behrens (2000) [1] defende a quebra desse paradigma, pois diante da velocidade com que o conhecimento passa a ser apresentado, a atitude de alguns docentes que procuram ensinar tudo sobre sua disciplina para os alunos torna-se impraticável. Dessa forma em vez de "bombardear" os alunos com conteúdos, o professor deve utilizar uma metodologia que promova uma aprendizagem ativa por parte do aluno, ou seja, o educador deve motivá-lo e direcioná-lo na busca pelo conhecimento, ensinando o discente a utilizar os recursos a sua volta como livros, vídeos, simuladores, internet, etc. Este modelo de educação requerido fica claro nas palavras de Freire (1996, p. 27) [2]: "ensinar não é transferir conhecimento, mas criar as possibilidades para a sua própria produção ou a sua construção".

A aprendizagem significativa de que fala Ausubel (1978 apud Moreira, 2011) [3] é outra ideia importante a levar-se em consideração no processo educacional. Conforme defende o autor a aprendizagem se torna significativa para o educando, quando o conteúdo a ser aprendido se relaciona com o seu conhecimento prévio, ou seja, para que um novo conhecimento adquira significado é necessário considerar o uso de toda a bagagem cognitiva do discente. No entanto quando não se consegue fazer essa interação, entre os conceitos relevantes que o educando já domina e aqueles que ainda estão por vir ocorre o que se chama de aprendizagem mecânica, onde o aprendiz apenas memoriza informações de maneira arbitrária sem saber correlacioná-las na compreensão do mundo a sua volta, dessa forma, o seu objetivo se restringe apenas em passar nas avaliações aplicadas pelo professor, atitude essa que o leva a esquecer facilmente o que estudou. Portanto o educador deve apresentar o conteúdo de uma forma que motive o discente a relacionar o novo assunto a sua estrutura cognitiva, que este tenha curiosidade e interesse em aprender sobre 
o conteúdo proposto, afim de que saiba aplicá-lo em situações diferentes daquelas usadas no eu ensino.

Vygotsky (2007) [4] também verifica a importância de se considerar o conhecimento préexistente para mediar o processo de construção de um novo conhecimento, no entanto o autor da uma nova compreensão entre está relação e as funções que já amadureceram e aquelas que ainda não amadureceram. Vygotsky defende o conceito de "Zona de Desenvolvimento Proximal" (ZDP), para ele todo o conhecimento do discente, ou seja, aquilo que já está alicerçado é chamado de nível de desenvolvimento real e aquilo que ele não domina mais que poderá a vir aprender com a ajuda de outro mais capaz, como um professor, por exemplo, é chamado de nível de desenvolvimento potencial, e é está distância entre estes dois extremos que se define como ZDP, uma zona cognitiva onde os estudantes são ainda capazes de solucionar problemas se assistidos. A ajuda do professor nesse caso ocorre através de dicas, instruções, provocação de reflexões e utilização de recursos educacionais como livros, vídeos, simuladores, tutorias e internet principalmente.

É perceptível que as tecnologias do conhecimento estão mais próximas do que nunca, as pessoas, sobretudo os jovens, carregam nos bolsos celulares que possuem os mais diversos tipos de funções, entre elas a internet que proporciona informações de maneira rápida e em tempo real, além do acesso a outras ferramentas educacionais como vídeos, jogos e simuladores. $\mathrm{O}$ conhecimento passou a ficar condensado num aparelho portátil que cabe na palma da mão, onde para ter acesso basta um toque na tela ou o aperto de botão [5]. Através de aparelhos como Smartphone, os jovens principalmente, se comunicam pelas redes sociais compartilhando informações, imagens, vídeos, além de usarem no ambiente educacional, no entanto neste ambiente sua utilização muitas vezes não é admitida pelos docentes, muitos chegam até a proibir o uso durante as aulas. Porém, deve-se lembrar que estes aparelhos são ferramentas com um enorme potencial didático, mas raramente são aproveitados pedagogicamente.

Os estudantes de hoje, estão expostos a muito mais informação que os estudantes do passado, é sabido que mudanças tecnológicas e na sociedade, sempre refletiram na educação, logo não dá para continuar utilizando apenas uma ou duas metodologias de ensino, a informação não se encontra apenas escrita nos quadros e nos livros, estes não são os únicos locais em que o discente deve buscar conhecimento. Um novo tempo, um novo espaço, exige formas diferentes de pensar e educar, o amplo acesso e uso das novas tecnologias educacionais requerem novas metodologias na prática educacional [6].

Behrens (2000, p. 75, grifo do autor) [1] que defende o uso de TIC no ensino, argumenta que:

Para romper com o conservadorismo, o professor deve levar em consideração que, além da linguagem oral e da linguagem escrita que acompanham historicamente o processo pedagógico de ensinar a aprender, é necessário considerar também a linguagem digital. Neste processo de incorporação ele precisa propor novas formas de aprender e de saber se apropriar criticamente de novas tecnologias, buscando recursos e meios para facilitar a aprendizagem.

As TIC, caracterizadas como midiáticas, dessa forma não são apenas suportes, estas interferem nas atitudes dos usuários, no modo de pensar, na forma de se relacionarem socialmente e na forma de buscarem conhecimento, isso tudo leva a uma nova cultura e um novo modelo de sociedade [6]. No ambiente educacional Lévy (1993) [8] tem o posicionamento de que a multimídia interativa é um instrumento bem ajustado a uma pedagogia ativa, pois favorece uma atitude exploratória, até mesma lúdica, diante do assunto a ser assimilado.

Portando diante das teorias supracitadas verifica-se que com o uso de novas tecnologias, o discente passa a ter um papel mais ativo no âmbito escolar e o professor passa a atuar mais como um facilitador e orientador direcionando o educando na busca pelo conhecimento.

"Para exemplificar o que significa o uso de tecnologias no auxilio ao processo de ensino e aprendizagem, é possível pensarmos o que significaram os óculos para uma pessoa com dificuldades visuais, quando lentes foram inventados, por volta do século XIII" [9]. 


\subsection{FÍSICA NO ENSINO FUNDAMENTAL}

Dentre as áreas do conhecimento humano que juntas constituem as Ciências Naturais no ensino fundamental, os conteúdos de Física abordados nos anos finais, são vistos por muitos alunos como algo tedioso, que se resume em conceitos apresentados pelo professor ou contidos nos livros didáticos e também na memorização de fórmulas. Já são bem divulgadas as críticas ao ensino de Ciências em que se promove a memorização de conteúdos afim de que estes sejam reproduzidos em avaliações, o que tem resultado em uma aprendizagem momentânea sem muito significado para os estudantes. Por outro lado é notório, que as aulas de Física se tornam mais interessantes, com a aplicação de metodologias que proporcionem maior participação do discente no processo de ensino e aprendizagem e que garantam maior contextualização e ludicidade nos temas debatidos, dando a estes significados para que o discente possa utilizá-los na compreensão e interpretação de fenômenos naturais e tecnologias a sua volta [10].

É expressivo o número de alunos pelos mais diversos países que encontram dificuldades no aprendizado de Física nos vários níveis de ensino, onde entre as razões desse insucesso, são verificados através de métodos de ensino ultrapassados, que não levam em consideram as mais recentes teorias de aprendizagem, assim como a falta da utilização de recursos pedagógicos mais modernos como, por exemplo, as novas tecnologias de informação e comunicação[11].

A Física é uma ciência que tem como um de seus alicerces a experimentação, logo o professor ao trabalhar um assunto, necessita na maioria das vezes, realizar duas abordagens: uma teórica que geralmente acontece através de aulas expositivas e uma prática que deveria ocorrer em um laboratório de ciências, no entanto, são muitas as dificuldades na promoção destas aulas. Pires e Veit (2006) [12] expõem que as aulas experimentais são cada vez mais raras, pois poucas escolas têm condições de manter em funcionamento um laboratório para o ensino de Física. Além das dificuldades em se manter laboratórios de ciências funcionando nas escolas públicas pelo país, outro fator que dificulta as aulas experimentais, ocorre devido às particularidades de alguns experimentos como, por exemplo, alta periculosidade e custo elevado. Diante destes problemas, compreende-se a importância de se pensar em novas maneiras de proporcionar essa ludicidade às aulas de Física no ensino fundamental, umas das formas de contornar este problema, pode-se dar através dos novos recursos educacionais como o smartphone e os simuladores virtuais dentre outros.

Outro fator que chama a atenção para uma pedagogia que promova o uso de novas metodologias de ensino na Física deve-se ao fato dos Parâmetros Curriculares Nacionais (PCN), desaconselharem à comunicação direta das teorias científicas aos alunos do ensino fundamental devido a sua complexidade e alto grau de abstração, pois tais teorias estão distantes das ideias de senso comum dos educandos. Dessa forma o ensino de Física no ensino fundamental tem requerido estratégias pedagógicas, que amenizam essas abstrações e que também criem competências que levem os aprendizes a articularem o conhecimento físico com outras áreas do saber cientifico e que estes reconheçam o papel da Física na evolução dos meios tecnológicos e na explicação de diversas experiências do cotidiano [10].

\subsection{SIMULADORES}

Simulações são modelos computacionais que operam em representações matemáticas via linguagens de programação e que tem como finalidade fornecer animações que imitam situações e fenômenos reais ou imaginários [13]. Como exemplos, temos as simulações de manobras de aeronaves por pilotos em treinamento, a simulação do lançamento de um satélite por uma equipe de cientistas, ou mesmo de um procedimento cirúrgico para um médico em treinamento.

Devido a essa característica da simulação que permite que o indivíduo assimile o conhecimento de forma interativa, essa ferramenta pedagógica possui considerável interesse na educação, pois simulações tecnicamente e pedagogicamente bem elaboradas podem ser realizadas com bastante realismo. 
Nas palavras de Chaves (1988) [14] resume-se bem o conceito de simulação: "Uma simulação é um modelo que pretende imitar um sistema, real ou imaginário, com base em uma teoria de operação desse sistema."

As simulações também podem ser divididas em estáticas e interativas, na primeira o aprendiz possui pouco ou nenhum controle sobre os parâmetros, ou seja, proporciona pouca interatividade [15]. Nas simulações interativas a interação é possibilitada, pois é permitido manipular parâmetros e observar resultados imediatos, ocasionados pela modificação de situações e condições[16].

\subsection{O PAPEL PEDAGÓGICO DO SIMULAR.}

O uso de simuladores no ensino de Ciências permite que o saber científico seja potencializado. Através dessa mídia educacional, docentes desta disciplina podem trabalhar de forma mais lúdica, os fenômenos físicos, que na maioria das vezes são demasiadamente abstratos, para serem compreendidos, apenas através de textos e palavras por alunos do ensino fundamental. No entanto Kenski (2004) [6] alerta que, para o docente alcançar os objetivos pretendidos com a utilização deste recurso, o mesmo deverá saber utilizá-lo adequadamente procurando explorar o máximo suas especificidades.

Considerando as vantagens que o simulador proporciona ao ensino de Ciências, mais precisamente aos assuntos de Física, o que interessa em primeiro lugar, é o seu beneficio cognitivo. Ao manipular variáveis e parâmetros em uma simulação, o discente poderá ter uma melhor compreensão sobre as relações de causa e efeito presentes no modelo estudado, experiência está que não se assemelha ao conhecimento teórico, ou aula prática, nem mesmo ao acúmulo de uma tradição oral. Através da simulação o aprendiz tem ainda a vantagem de conseguir explorar modelos mais complexos e em maior número do que se usasse apenas a construção mental e sua memoria de curto prazo. Dessa forma está ferramenta tem a habilidade de ampliar a capacidade de imaginação e intuição do aluno, reconhecendo o potencial desta tecnologia educacional, Lévy (1993, p. 123) [8] expressa que: "O conhecimento por simulação é sem dúvida um dos novos gêneros de saber que a ecologia cognitiva informatizada transporta."

Os fenômenos e conceitos mais diversos da Física são possíveis de serem trabalhados através da simulação, no entanto as principais vantagens desse recurso comparadas às aulas experimentais devem-se ao fato de em um ambiente virtual, não se colocar os alunos em risco ao trabalhar com experimentos que proporcionam perigo, também se tem a vantagem de trabalhar experiências difíceis ou inviáveis de realizar na prática seja por ser muito caras ou por ocorrerem de forma demasiadamente rápidas ou lentas [11]. Dessa forma, como exemplo, pode-se trabalhar através de simuladores, com experimentos de óptica como será demonstrando mais a frente assim como também de eletricidade, mecânica, termodinâmica e até mesmo física moderna.

Chaves (1988) [14], no entanto alerta que se deve atentar que depois do trabalho com simuladores, o professor precisa dar explicações aos alunos sobre os pressupostos utilizados na elaboração daquele modelo, de maneira a levar os discentes a compreenderem o porquê do modelo se comportar dessa, ou daquela forma e que também tenham em mente as limitações envolvidas no processo. $\mathrm{O}$ autor ainda recomenda que considerando os graus de escolaridade, as simulações mais sofisticadas que às vezes exigem certo nível de abstração, devem ser utilizadas no ensino médio ou superior, enquanto as menos sofisticadas, ou de fácil manipulação possam ser usadas com proveito nos graus inferiores. Outro ponto a se destacar é o uso principalmente das simulações interdisciplinares, por levarem os alunos a compreenderem a Física em um contexto mais amplo, o que torna assim as aulas mais interessantes e com significado.

Em resumo diante dos benefícios já explanados do uso de simulações virtuais no ensino de Ciência, tais mídias possuem ainda a capacidade de:

Permitir aos estudantes gerarem e testarem hipóteses; engajar os estudantes em tarefas com alto nível de interatividade; envolver os estudantes em atividades que explicitem a natureza da pesquisa científica; tornar conceitos abstratos mais concretos; reduzir a ambiguidade e ajudar a identificar relacionamentos de causas e efeitos em sistemas complexos; servir como uma preparação inicial 
para ajudar na compreensão do papel de um laboratório; promover habilidades do raciocínio crítico; fomentar uma compreensão mais profunda dos fenômenos físicos; acentuar a formação dos conceitos e promover a mudança conceitual $[\ldots][13]$.

\subsection{CUIDADOS COM O USO DE SIMULADORES}

As simulações como visto, possuem muitas vantagens no ambiente educacional, no entanto se estas não forem utilizadas corretamente pode também trazer alguns prejuízos ao ensino. $\mathrm{Na}$ utilização de simuladores virtuais o docente deve esclarecer aos discentes que o modelo apresentado é apenas uma representação da realidade, pois se assim não for, corre-se o risco dos estudantes conceberem em suas mentes que os fenômenos da natureza ocorrem exatamente como verificados na simulação, o que é um erro. Os educandos precisam ser alertados que devem fazer suas deduções com base não sobre a simulação mais sobre a realidade[17].

Dessa forma, como a simulação nunca é uma reprodução fiel do real, devido não ser possível representar toda a complexidade de um fenômeno físico, por exemplo, esse recurso possui simplificações e aproximações da realidade, o que acarreta a existência de algumas simulações com erros grosseiros, outras com exagero nas animações, podendo assim repassar imagens distorcidas para os discentes, ou seja, opostas àquelas que o educador pretendia veicular, levando a uma interpretação equivocado dos conceitos estudados, o que poderá vir a provocar danos enormes [13].

Outro ponto a se destacar é que não se podem substituir completamente as aulas em laboratório por simulações virtuais, pois uma completa a outra e devem ser trabalhadas associadas. Um aluno nunca vai aprender através de uma simulação, a produzir uma fogueira, ou ter a experiência de sentir seus cabelos arrepiados ao tocar um gerador de "Van de Graaff", ou a confeccionar com as próprias mãos experimentos simples que ilustram muitos fenômenos físicos, etc. Também se deve atentar para a escolha dos simuladores a serem utilizados, como existem muitos softwares comerciais de baixa qualidade, o docente deve levar em consideração o preço, se possível optando pelos gratuitos de sites educativos, observar a qualidade técnica e acima de tudo a qualidade pedagógica [14].

\section{5. ÓPTICA: DEFEITOS DA VISÃO.}

Com base nos PCN e teorias de aprendizagem discutidas neste artigo, o tema "Defeitos da Visão", foi escolhido, como assunto para ser estudado no ensino fundamental utilizando simuladores via smartphone. Este assunto é um ótimo exemplo de como se trabalhar com conteúdos de Físicas de forma contextualizada. Ao explicar para os discentes como a luz chega aos olhos e se converte em imagens no cérebro, o docente precisa levar em considerações uma descrição pormenorizada do globo ocular que cabe à biologia; porém, cumpre ressaltar que o funcionamento do olho, como sistema óptico, envolve principalmente conceitos físicos.

Nesse tema o docente poderá trabalhar a anatomia do olho humano, os defeitos da visão, o conceito de difração da luz, lentes esféricas (divergentes e convergentes) e os instrumentos ópticos. Além da utilização dos simuladores que serão explicados mais a frente. $\mathrm{O}$ docente também poderá realizar alguns experimentos em laboratório, e tomar alguns discentes que usam óculos como exemplo, explicando para a turma o tipo de problema visual que o discente tem e como as lentes dos óculos que estes usam corrigem tal problema.

Trabalhando desta forma, o assunto tende a tornar-se relevante para o estudante, pois este verá os conceitos físicos de forma contextualizada e inter-relacionados com outras áreas do saber científico, além da aplicação dos conceitos estudados, aplicados na construção de instrumentos ópticos como lentes que ajudam a corrigir problemas relacionados à visão. Com essa metodologia de ensino, pretende-se que o discente compreenda a Física presente na natureza e nos equipamentos e procedimentos tecnológicos como, por exemplo, no funcionamento de determinados instrumentos ópticos, dando assim sentido aos assuntos estudados que têm como consequência uma aprendizagem significativa. 


\section{RESULTADOS E DISCUSSÕES}

Para trabalhar com o tema, "Defeitos da Visão" foram escolhidos dois simuladores, o simulador "O Olho Humano" (figura 1a), que aborda a anatomia do olho humano e o simulador, "Defeitos Visuais" (figura 1b) que trabalha com os principais defeitos da visão e os tipos de lentes de correção para estes problemas. Ambos os simuladores são gratuitos e foram produzidos pelo Sistema Brasileiro de Ensino S. A. (SEB), uma respeitada instituição educacional do Brasil, com mais de 50 anos no mercado da educação.

Os simuladores podem ser baixados a partir de um aparelho smartphone com sistema operacional android, através do aplicativo Play store (figura 1c). Para isso o aparelho deve estar conectado a internet, sendo assim é importante que a escola disponibilize internet $\mathrm{Wi}-\mathrm{Fi}$. No entanto caso a escola não ofereça esse recurso, o docente poderá a partir de um único aparelho que tenha acesso a internet baixar os simuladores indicados, assim como outro programa que permita o compartilhamento de aplicativos via Bluetooth como, por exemplo, o aplicativo AppShare (figura 1d), dessa forma pode-se compartilhar os simuladores com todos os demais smartphone via bluetooth.

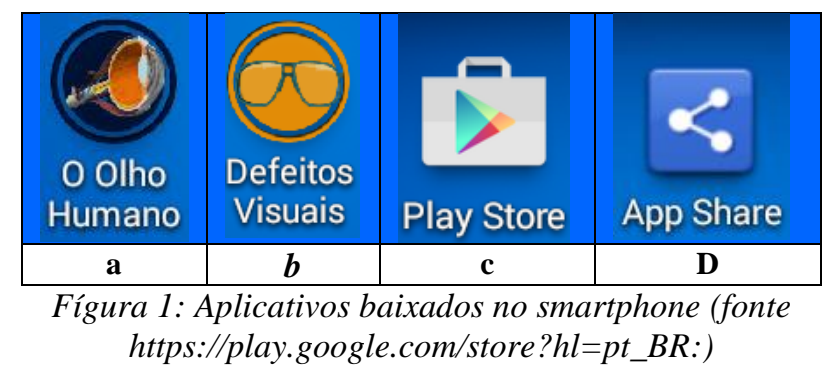

Um fator negativo se deve ao fato de nem todo estudante possuir um smartphone, no entanto a principal finalidade da proposta é saber fazer uso desta ferramenta em sala de aula de forma a trazer contribuições para o ensino, logo o professor para contornar a situação, poderá formar grupos, a fim de que cada um tenha pelo menos um aparelho. O importante é que todos aprendem a baixar os simuladores e que saibam utilizá-los, pois mesmo aqueles que não possuem o aparelho, podem estar utilizando o smartphone dos pais, dos irmãos ou mesmo de amigos, o que têm como consequência positiva a disseminação de conhecimento científico.

\subsection{APLICATIVO: SIMULADOR "O OLHO HUMANO"}

Ao executar o simulador "O Olho Humano", o aplicativo inicia apresentando alguns questionamentos ao aluno, que tem como objetivo levá-lo a refletir sobre o que são determinadas estruturas como retina, pupila e cristalino e em que parte do globo ocular estas se localizam (figura 2). Ao clicar no ícone play aparece em 3D um rosto humano que aos poucos vai sendo "dissecado" mostrando para o aluno como os olhos estão possicionados no crânio e as estruturas que os constituem. 


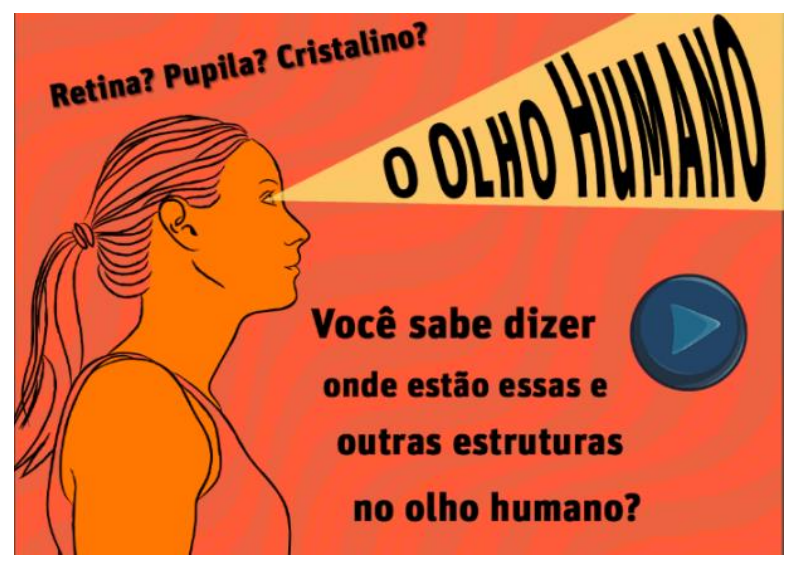

Fígura 2:Página inicial do simulador: O Olho

Humano.

O globo ocular é apresentado com um corte transversal, o que facilita ao aluno uma melhor visualização e compreensão de suas estruturas, esse esboço em 3D pode ser rotacionado permitindo diferentes ângulos de visualização, o aluno pode ainda clicar no ícone de qualquer estrutura, que uma caixa de texto será apresentada informando sua função (figura 3). Através deste simulador o educando poderá ter uma melhor visualização de estruturas mais internas dos olhos como, por exemplo, o nervo óptico, a retina e os musculos ciliares dado a possibilidade de manipulação da imagem.

Dentre as definições que o simulador apresenta referentes as estruturas do globo ocular algumas merececem destaque, quanto ao mecanismo de funcionamento da visão:

- Pupila: abertura localizada no centro do olho que permite a entrada de luz;

- Córnea: desvia os raios luminosos que atingem o olho, direcionando-os para a pupila;

- Cristalino: desvia os raios luminosos com maior precissão, para que a imagem se forme na posição devida;

- Retina: região onde se formam as imagens. Possui células especializadas que transformam a luz em impulsos nervoso.

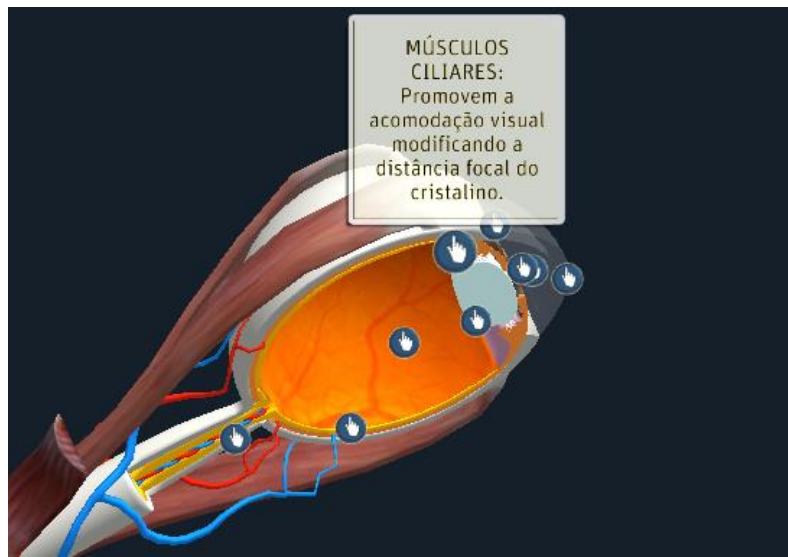

Fígura 3: Globo ocular em corte transversal, apresentando caixa de texto com a função dos Músculos Ciliares.

Como atividade o simulador apresenta um esboço do globo ocular, onde o educando terá que correlacionar o nome das estruturas com suas lacunas correspondentes, para isto o aluno deverá arrastar os nomes das estruturas para suas localizações corretas (figura 4). Ao preencher todos os espaços relativos as estruturas, surgirar o ícone "corrigir", o aluno deverá clicar no ícone, se tudo estiver certo o simulador avisará, porém se estiver algumas estruturas com a localização errada, apenas estas retornaram para o local de origem, então o aluno saberá que trocou a ordem entre estas e tentará novamente até o simulador avisar que a tarefa foi realizada com sucesso. Umas das contribuições desta atividade se deve ao fato da interação permitida do aluno com o assunto estudado e a possibilidade de o aluno também aprender por tentativa e erro através da análise de suas repostas e possíveis alterações. 


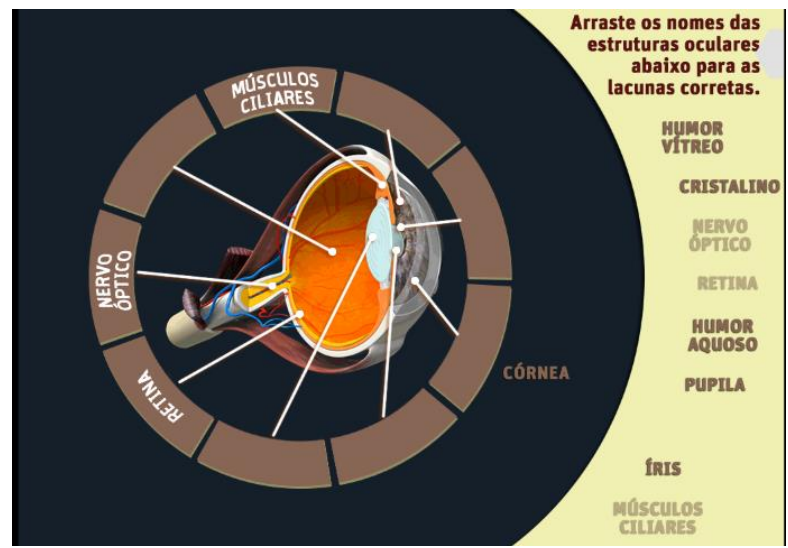

Figura 4: Atividades (relacionar os nomes as respectivas lacunas correspondentes).

\subsection{APLICATIVO: SIMULADOR "DEFEITOS VISUAIS"}

Ao executar o aplicativo "Defeitos Visuais", o simulador inicia apresentando como interface a imagem de óculos com lentes corretivas e alguns questionamentos sobre o que são os defeitos visuais como a miopia e o astigmatismo (figura 5). Ao clicar no ícone play aparece a imagem do globo ocular de um observador que está a olhar através da janela de um prédio (figura 6).

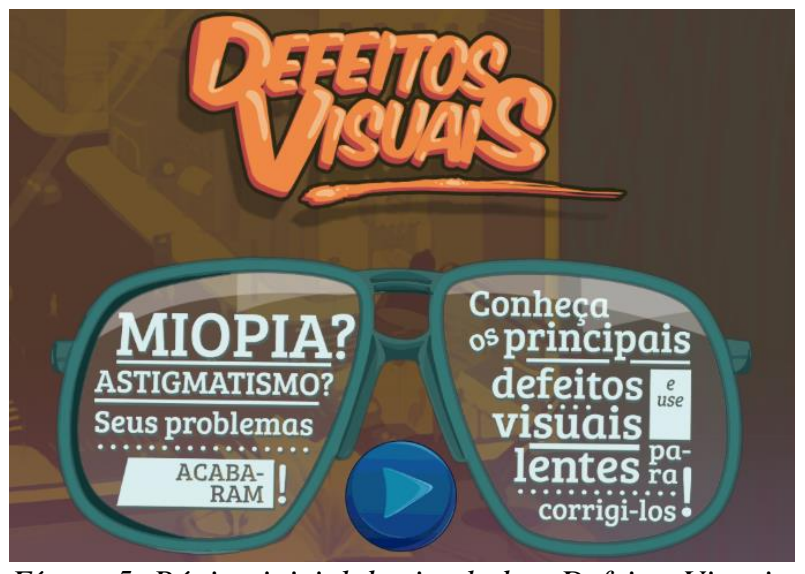

Fígura 5: Página inicial do simulador: Defeitos Visuais.

Como se pode observar na figura 6 , o simulador apresenta um modelo de visão normal, o indivíduo no caso ver com perfeição tantos os objetos que estão próximo como os distantes, para isso a distância focal do cristalino varia devido à atuação dos músculos ciliares, que provocam variações nas curvas das faces do cristalino que funciona como uma lente flexível e deformável. Se o mesmo fosse fixo a imagem que ele fornece do objeto nem sempre se formaria na retina [18]. O simulador apresenta ainda o nome dos principais defeitos da visão, ao clicar em qualquer um destes, aparecerá um texto informativo sobre o defeito visual e as imagens do cenário também sofrerão distorções conforme o defeito visual escolhido. É importante que o docente explique que as imagens se formam na retina de maneira invertida já que o simulador não fornece essa informação, evitando assim que o aluno tenha uma interpretação errônea do mecanismo de formação das imagens nos olhos.

A partir dessa ilustração interativa que simulador apresenta o docente poderá aproveitar para falar ainda que os objetos são possíveis de serem vistos por causa da luz que eles emitem, quer seja luminoso, quer seja iluminado, que os raios de luz se propagam em linha reta em um meio homogêneo e também poderá abordar os conceitos de corpos opacos e corpos transparentes. 


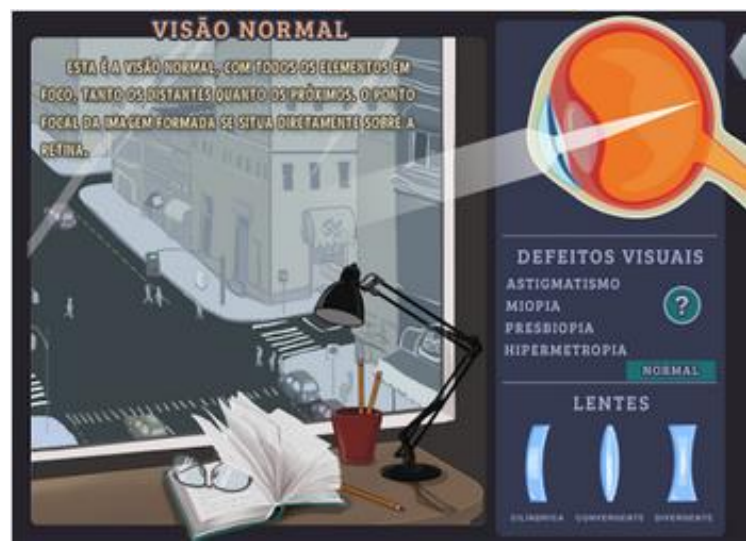

Fígura 6: Modelo de visão de um observador normal.

Clicando no nome miopia do simulador (figura 7), aparecerá o seguinte texto informativo:

“O míope não enxerga bem de longe, mas consegue ver bem de perto. O ponto focal da imagem formada se situa antes da retina. A principal causa é o formato de o olho ser um pouco mais alongado do que o normal, mas também pode ser causada por alterações no formato da córnea ou do cristalino. A lente para corrigir a miopia deve deslocar o ponto focal para trás, aproximando-o da retina. (Texto do aplicativo: App Defeitos Visuais APK)"

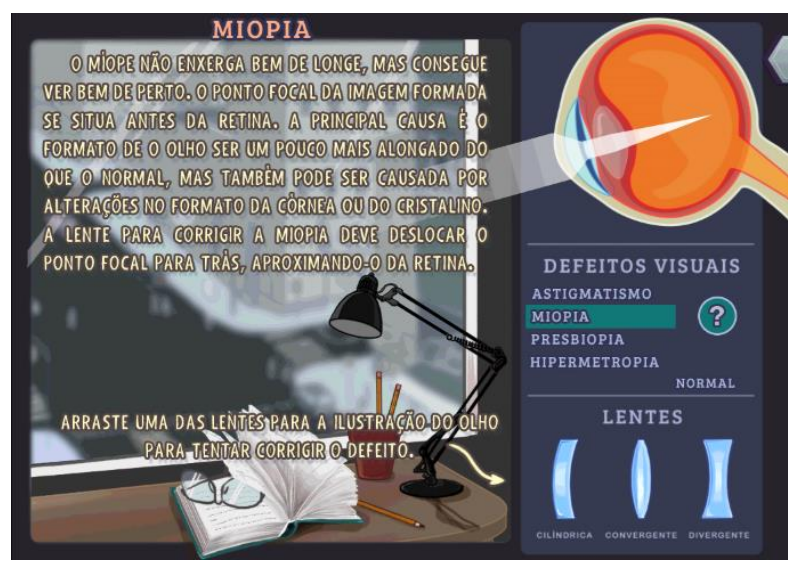

Fígura 7 - Modelo de visão de um observador míope.

Na figura 7 é possível verificar que o simulador mostra um modelo que representa a visão de uma pessoa com miopia, pode-se observar que os materiais que estão próximo ao observador, ou seja, sobre a mesa, estes objetos são enxergados perfeitamente, porém a imagem que ele enxerga através da janela apresenta-se sem nitidez, devido a grande distância que se encontra. É interessante o docente comparar com o modelo de visão normal representado na figura 6 .

O simulador permite também que o aprendiz arraste uma das lentes, posicionando-a na frente do olho e confira o resultado, se a lente escolhida não for apropriada o simulador apresentara a seguinte frase "Nossa! Ficou ainda pior tente outra lente". Por exemplo, se para uma míope for escolhido uma lente convergente o foco da imagem se afastara ainda mais da retina e se aproximara mais do cristalino. Na figura 8 mostra-se a escolha de uma lente correta, ou seja, uma lente divergente (bicôncava). Logo para uma pessoa que sofre de miopia o oftalmologista indicara óculos com lentes divergentes adequadas a cada caso, que reduzem a convergência dos raios luminosos, fazendo com que a imagem se forme na retina. $\mathrm{O}$ docente poderá aproveitar para informar ao aluno que o cristalino se trata de uma lente convergente (biconvexa) e explicar seu funcionamento[19]. 


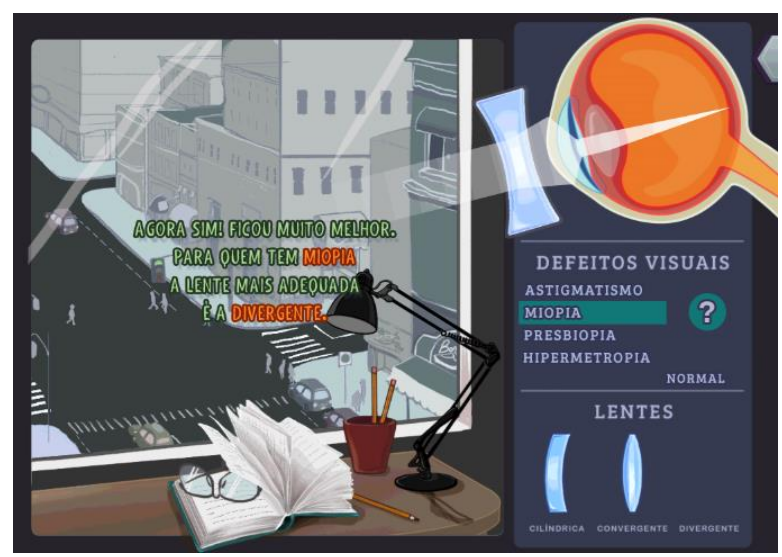

Fígura 8: Modelo de visão de um miope utilizando lentes corretivas divergentes.

Além da miopia o aplicativo aborda ainda os defeitos visuais astigmatismo, presbiopia e hipermetropia, dessa forma seguem-se as definições apresentadas pelo simulador para cada caso:

\begin{abstract}
"O hipermetrope vê melhor de longe do que de perto. Ponto focal da imagem formada se situa depois da retina. A principal causa é o formato de o olho ser um pouco menor do que o normal, mas também pode ser causada por alterações no formato da córnea ou do cristalino. A lente para corrigir a hipermetropia deve deslocar o ponto focal para frente, aproximando-o da retina. A presbiopia é também chamada de vista cansada e leva à diminuição da capacidade de focalizar objetos próximos. Ela é uma alteração natural que ocorre com o envelhecimento e costuma se manifestar depois dos 40 anos. A causa principal é a diminuição da elasticidade do cristalino. A lente para corrigir a presbiopia deve deslocar o ponto focal para frente, aproximando-o da retina. O astigmata tem dificuldades para ver tanto de perto como de longe. Os objetos são vistos deformados e é difícil perceber contrastes entre linhas. Existem inúmeros pontos focais para a imagem formada, ao invés de apenas um. $\mathrm{O}$ astigmatismo é causado por irregularidades no formato da córnea ou do cristalino. A lente para corrigir o astigmatismo deve concentrar os raios luminosos em um único plano, permitindo a formação de um único ponto focal (Texto do aplicativo: App Defeitos Visuais APK)."
\end{abstract}

Quando a presbiopia (figura 9c) é importante informar para o aluno que este defeito na visão é semelhante à hipermetropia (figura 9b), porém suas causas são diferentes, quando vem associada com a miopia, a correção da presbiopia é feita mediante o uso de lentes bifocais (ou multifocais), que têm uma região destinadas a objetos longínquos e outra o objetos próximos [18].

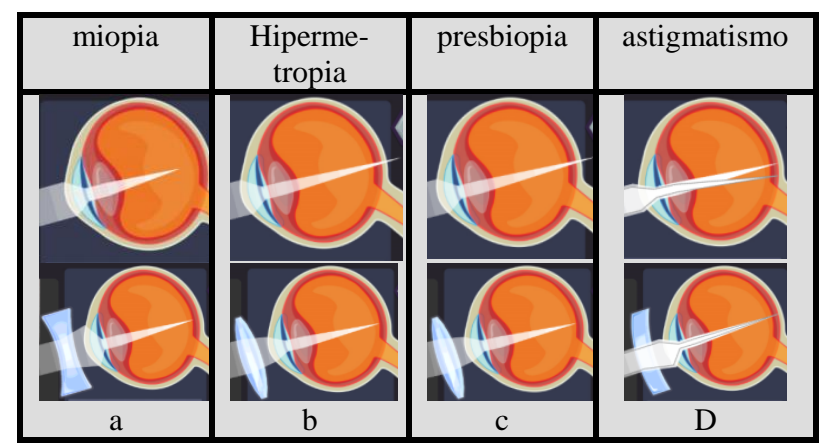

Figura 9 - Defeitos visuais e lentes corretivas correspondentes. 


\section{CONSIDERAÇÕES FINAIS}

Este artigo surgiu da necessidade de amenizar dois problemas enfrentados por muitos docentes: o uso inadequado do smartphone em sala de aula por parte dos discentes e as dificuldades em se promoverem aulas experimentais nas series finais do ensino fundamental voltadas para o estudo de conceitos e fenômenos físicos.

Os smartphones são aparelhos que fazem parte principalmente da cultura dos jovens, e por ser uma ferramenta bastante versátil e interativa, os discentes relutam em deixar de utilizá-los mesmo durante as aulas, seja para ouvir música, ou acessarem a internet ou se comunicarem em redes sociais. Dessa forma, a decisão mais coerente a ser tomada pelo docente e se apropriar dessa rica ferramenta de acesso à informação, de maneira a promover seu uso de forma pedagógica no âmbito escolar.

A meta deste trabalho, portanto consistiu na apresentação de metodologias voltadas para o uso de simuladores via smartphone, com o objetivo de trazer mais ludicidade aos conteúdos de Física na disciplina de Ciências Naturais. As propostas foram realizadas com base nas teorias de aprendizagem exposta no referencial teórico e nos PCN. Sendo assim, foram apresentadas algumas estratégias que se voltam a garantir que o discente aprenda de forma participativa, ou seja, que o discente possa ser um agente ativo no processo de ensino e aprendizagem. Evoluindo assim de uma educação tradicional, baseada apenas na transferência de conhecimento, onde o professor procura impor um conteúdo já pronto, que não estimula o engajamento intelectual do aluno, para um modelo construtivista, no qual, procura-se estimular no discente a reflexão e o pensamento crítico sobre o conteúdo a ser trabalhado.

Dentre os vários recursos disponíveis via smartphone, optou-se pelos simuladores dado a interatividade que estes promovem entre aluno é os conteúdos. São muitas as vantagens, podem ser acessados de um aparelho portátil que cabe na palma da mão, muitos são gratuitos, descrevem fenômenos que seriam muito difíceis de serem realizados na prática até mesmo em laboratório e, além disso, tem a característica de acionar vários canais sensoriais durante o aprendizado, o que garante uma melhor fixação da informação, além de também dar um caráter de jogo aos conteúdos apresentando-os de maneira divertida.

Para tomar como exemplo, da aplicação desta ferramenta no ensino de Ciências optou-se pelo conteúdo de "Defeitos da Visão", pois através deste foi possível trabalhar de forma contextualizada a Física em paralelo com Biologia, além de ser possível verificar os conceitos estudados aplicados em algumas tecnologias o que torna assim os assuntos com mais significado para os discentes, satisfazendo portanto o que orienta os PCN. Através das atividades propostas, é possível apresentar conceitos básicos de óptica de maneira menos abstrata e assim mais atraente ao aluno, o que propicia melhor compreensão dos modelos físicos e maior envolvimento destes durante as aulas.

É importante também lembrar, que na utilização de simuladores o docente deve alertar para os discentes que as simulações são apenas representações da realidade e não uma reprodução fiel, e estas também não devem substituir por completo as aulas em laboratório, o ideal e trabalhar essas metodologias em conjuntos.

Além das metodologias de utilização de simuladores via smartphones aqui abordadas, o educador também poderá estar utilizando outros recursos midiáticos através deste aparelho no ensino, como: vídeos que podem ser acessados no YouTube, ou mesmo serem produzidos pelo docente junto com a turma; pode-se fazer grupos para discussão de temas referentes as aulas no Facebook ou WhatsApp; além da utilização de outros aplicativos como calculadora, dicionários e tradutores de línguas.

\section{AGRADECIMENTOS}

Os autores agradecem a Coordenação de Aperfeiçoamento de Pessoal de Nível Superior (CAPES) pelo aporte financeiro. 


\section{REFERÊNCIAS}

1. Behrens, M.A. Projetos de Aprendizagem Colaborativa num Paradigma Emergente. ln: Moran J. M., Masetto M. T., Behrens M.A. Novas Tecnologias e mediação pedagógica. 3. ed. Campinas (SP): Papirus; 2000. p. 67-129.

2. Freire P. Pedagogia Da Autonomia: Saberes Necessários à Prática Educativa. São Paulo: Paz e Terra; 1996.

3. Moreira, M.A., Teorias de Aprendizagem. 2. ed. São Paulo: EPU; 2011. 242 p.

4. Vygotsky, L.S., A Formação Social da Mente: o desenvolvimento dos processos psicológicos superiores. 7 ed. São Paulo: Martins Fontes; 2007. 182 p.

5. Smolka, A.L.B., Magiolino, L.L.S., História da Pedagogia: Modos de ensinar, sentir e pensar. Revista Educação. 2010 ago; 2: 30 - 39.

6. Kenski, V.M., Tecnologias e ensino presencial e a distância. 2. ed. Campinas: Papirus; 2004. 157 p.

7. Freire P. Pedagogia Do Oprimido. 17. ed. Rio de Janeiro: Paz e Terra; 2005. 184.

8. Lévy P. As tecnologias da inteligência: o futuro do pensamento na era da informática. Rio de Janeiro: 34 Ltda; 1993. 208 p.

9. Barros, D.M.V., Guia didático sobre as tecnologias da comunicação e informação: material para o trabalho educativo na formação docente. Rio de Janeiro: Vieira \& Lent; 2009. 160 p.

10. Brasil. Ministério da Educação, Secretaria de Educação Fundamental. Parâmetros curriculares nacionais: Ciências Naturais - Ensino de $5^{\mathrm{a}}$ a $8^{\mathrm{a}}$ séries. [internet]. Brasília: MEC/SEF; 1998. 138 p. [acesso 2015 jan 20]. Disponível em http://portal.mec.gov.br/seb/arquivos/pdf/ciencias.pdf.

11. Fiolhais, C., Trindade J., Física no Computador: o Computador como uma Ferramenta no Ensino e na Aprendizagem das Ciências Físicas. Revista Brasileira de Ensino de Física. [internet]. 2003. [acesso 2015 jan 10]; 25(3): 259-272. Disponível em http://www.sbfisica.org.br/rbef/pdf/v25_259.pdf.

12. Pires, M.A., Veit E.A., Tecnologias de Informação e Comunicação para ampliar e motivar o aprendizado de Física no Ensino Médio. Revista Brasileira de Ensino de Física. [internet]. 2006. [acesso 2015 jan 10]; 28(2): 241-248. Disponível em http://sbfisica.org.br/rbef/pdf/050903.pdf.

13. Medeiros, A., Medeiros, C.F., Possibilidades e limitações das simulações computacionais no ensino da física. Revista Brasileira de Ensino de Física. [internet]. 2002. [acesso 2015 jan 10];24(2):77-86. Disponível em http://www.sbfisica.org.br/rbef/pdf/v24_77.pdf.

14. Chaves, E.O.C., O Uso de Computadores em Escolas: Fundamentos e Críticas [internet]. São Paulo: Scipione; 1988. [acesso 2015 jan 10] Disponível em http://www.ich.pucminas.br/pged/db/wq/wq1/local/ec_scipione.htm.

15. Coelho, R.O., O Uso da Informática no Ensino de Física de Nível Médio. [Dissertação] [internet]. Pelotas: Universidade Federal de Pelotas; 2002. [acesso 2015 jan 10]. Disponível em http://www2.pelotas.ifsul.edu.br/coelho/inf_ens_fis_med.pdf.

16. Heckler, V., Saraiva M.F.O., Oliveira Filho, K.S., Uso de simuladores, imagens e animações como ferramentas auxiliares no ensino/aprendizagem de óptica. Revista Brasileira de Ensino de Física. 2007. [internet]. [acesso 2015 jan 10]; 29(2): 267-273. Disponível em http://www.scielo.br/pdf/rbef/v29n2/a11v29n2.

17. Oliveira, R., Informática educativa: Dos planos e discursos à sala de aula. 15 ed. Campinas (SP): Papirus; 1997. $176 \mathrm{p}$.

18. Canto, E.L., Ciências Naturais: aprendendo com o cotidiano. 3 ed. São Paulo: Moderna; 2009.

19. Nery, A.L.P., Killner, G.I., Ciências $9^{\circ}$ ano: ensino fundamental. 3 ed. São Paulo: Edições SM, 2012. 